\title{
Contribuições da Filosofia de Giorgio Agamben à Leitura do Caso Justransicional Colombiano
}

\section{Contributions from Giorgio Agamben's Philosophy to the Reading of the Colombian Justransicional Case}

\author{
Fernando Cardoso ${ }^{1}$ \\ Universidade de Pernambuco (Brasil) \\ Jessyca Iasmim de Souza ${ }^{2}$ \\ Centro Universitário do Vale do Ipojuca (Brasil)
}

Recibido: 14-10-17

Aprobado: 08-01-18

\section{Resumo}

A presente pesquisa problematiza a concepção de estado de exceção proposta por Giorgio Agamben e sua perpetuação nas democracias atuais, a partir da leitura do conflito existente na Colômbia. Para tanto, objetivou-se compreender quais as contribuições da filosofia de Giorgio Agamben à leitura do caso justransicional colombiano. A partir dos conceitos de estado de exceção, de biopoder, de força e de justiça de transição reflete-se como o caso colombiano aduz a uma nova concepção de estado de exceção e de quadro justransicional. Através das reflexões construídas com base na filosofia de Agamben, acredita-se que contexto jurídico-político colombiano perpetua marcadores de totalitarismo a partir das normas e na relação entre governantes e governados. A existência de aspectos ligados à instabilidade político-constitucional interfere diretamente no modo como o Estado age em relação ao diálogo com seu povo e, no caso colombiano, impossibilita a afirmação de um quadro justransicional pleno. O pós-conflito, no quadro justransicional colombiano, necessita refletir à desconstrução de

\footnotetext{
${ }^{1}$ (cardosodh8@gmail.com). Mestre em Direito Humanos - Universidade Federal de Pernambuco e Doutorando em Direito - Pontificia Universidade do Rio Janeiro. Professor Assistente da Universidade de Pernambuco, Brasil.

2 (jessycaiasmim@hotmail.com ). Graduada em Direito - Centro Universitário do Vale do Ipojuca e Integrante do Grupo de Estudos e Pesquisas Interdisciplinares sobre Direitos Humanos (GEPIDH/ UNIFAVIP), Brasil.
} 
aspectos totalitários mantidos no quadro jurídico, especialmente no que se refere à superação das marcas da colonização no processo de formação constitucional do país.

Palavras-chave: Giorgio Agamben, Estado de exceção, Justiça de transição, Colômbia.

\begin{abstract}
The present research problematizes the conception of state of exception proposed by Giorgio Agamben and its perpetuation in the present democracies, from the reading of the conflict existing in Colombia. In order to do so, the objective was to understand the contributions of Giorgio Agamben's philosophy to the reading of the Colombian justransicional case. From the concepts of state of exception, biopower, force and transitional justice, it is reflected in how the Colombian case leads to a new conception of the state of exception and the justransional framework. Through reflections built on Agamben's philosophy, it is believed that the Colombian legal-political context perpetuates markers of totalitarianism based on norms and on the relationship between rulers and governed. The existence of aspects related to politicalconstitutional instability directly interferes with the way in which the State acts in relation to the dialogue with its people and, in the Colombian case, makes it impossible to affirm a full juridical framework. Post-conflict, within the Colombian justransicional framework, needs to reflect the deconstruction of totalitarian aspects maintained in the legal framework, especially with regard to the overcoming of the colonization marks in the process of constitutional formation of the country.
\end{abstract}

Key-words: Giorgio Agamben, State of Exception, Transitional Justice, Colombia.

\title{
1. Introdução
}

Amparada pelo estado democrático de direito e objetivando reafirmar os direitos humanos, a justiça de transição é o ramo do direito que almeja a reparação daqueles que sofreram violações de direitos durante a vigência dos estados de exceção ocorridos no passado. Assim, busca reestruturar a sociedade pós-conflito atribuindo responsabilidades aos agentes violadores, exigindo a efetividade do direito à memória, à verdade e à reparação, visando garantir a não repetição de atrocidades. Para tanto, faz uso de mecanismos, judiciais, extrajudiciais e abordagens humanitaristas que fortalecem as instituições democráticas. 
A respeito disso, o conceito de estado de exceção trazido pelo filósofo Giorgio Agamben pode significar uma lente para a releitura dos casos pósconflito na América Latina. Nesse sentido, Agamben (2010) conceitua o estado de exceção como sendo a forma legal daquilo que não pode ter forma legal, sendo, portanto, o ponto de desequilíbrio entre o direito e o fato político, vez que se encontra no limite entre a política e o direito.

Nesse sentido, importa analisar o atual caso justransicional colombiano entre o governo colombiano e as FARC (Forças Armadas Revolucionárias da Colômbia) grupo de revolucionários inspirados em ideais comunistas que visam uma revolução social no estado colombiano3.

Assim, na democracia colombiana, existe uma espécie de exceção governada pelo Estado e por aqueles que resistem, supostamente a uma dada forma de governo. Este quadro jurídico-político alude ao pensamento de Agamben, quando afirma que as democracias, de certa forma, legitimam a criação dos estados de exceção. Nesse sentido o presente trabalho refletiu sobre a seguinte questão de pesquisa: quais as contribuições da filosofia de Giorgio Agamben à leitura do caso justransicional colombiano?

Para tanto, instituiu-se como objetivo geral compreender quais as contribuições da filosofia de Giorgio Agamben à leitura do caso justransicional colombiano. Através dos objetivos específicos visou-se: demonstrar, através da filosofia de Giorgio Agamben, a perpetuação do estado de exceção nas democracias atuais; interpretar o conceito clássico de Justiça de Transição analisando os quadros permanentes de violação de Direitos Humanos pósconflito; e, reler o caso justransicional colombiano à luz das contribuições do pensamento de Giorgio Agamben.

A justiça de transição na América Latina, de forma geral, se limita a investigar, relatar e buscar a reparação a graves violações de direitos humanos ocorridas em períodos de exceção, deixando à margem, muitas vezes, discussões atuais sobre a perpetuação de violências instituídas a partir de regimes de totalitarismo, implícitas em mecanismos "democráticos" ainda existentes em diferentes ordens jurídicas.

Nesse sentido, por ser um campo de reflexão incipiente, no que se refere à busca por compreender a finalidade e sua aplicação na contemporaneidade, pesquisas que evidenciam e corroboram para a discussão sobre a justiça de transição são de extrema importância. Afinal, este campo, ao mesmo tempo que lida com danos antes vistos como irreparáveis, evidencia direitos humanos previstos histórica e internacionalmente, alguns desconhecidos por maior parte da sociedade, buscando uma atuação pautada em políticas para o "nunca mais",

\footnotetext{
${ }^{3}$ Marcados, por um lado, pela violência colonial-estatal e, por outro, pelo incentivo bélico oferecido por potências bélicas ocidentais, o conflito gestado a partir das ações das FARC é, hoje, tema de grandes discussões e controvérsias no cenário de pesquisas no/do direito internacional, das relações internacionais e dos estudos sobre a América Latina.
} 
ou seja, utilizando a memória e a verdade como instrumentos de garantia da não repetição do passado autoritário que Estados e sociedades presenciaram.

Acredita-se que o que dificulta, nas sociedades atuais, a consolidação da justiça de transição é a perpetuação de práticas e políticas autoritárias que sustentaram as ditaduras, fazendo-se com que resquícios destes regimes ainda estejam presentes no panorama de diversas democracias, especialmente na América Latina.

A justiça de transição ainda possui um campo de atuação restrito, que deve ser problematizado. Deve-se pensar para além de períodos de exceção que já se findaram e problematizar os legados autoritários presentes e novamente aparelhados nos novos estados de exceção. É o que ocorre, por exemplo, na Colômbia, com a violenta continuidade do conflito entre as Forças Armadas Revolucionárias da Colômbia (FARC) e o Estado, situação que dura há mais de 52 anos, tencionando a existência de políticas de exceção em um panorama "democrático".

Assim, a pesquisa utilizou-se do método hipotético-dedutivo, definido por Karl Popper apud Lakatos e Marconi (2003) como o mais lógico a se aplicar em pesquisas científicas de cunho filosófico, vez que reflete um dado problema e apresenta hipóteses, aplicando-as ao caso para que sejam falseadas e/ou corroboradas.

Levando-se em conta que a proposta da pesquisa é realizar um debate crítico a respeito dos conceitos de estado de exceção e da justiça de transição, se fez uso do tipo de abordagem fenomenológica, abordagem essencialmente filosófica (Duarte e Fonseca, 2014).

Utilizou-se os tipos de pesquisa exploratório e bibliográfico. Para Gil (2008), esses tipos de pesquisa são essenciais quando da utilização e discussão de materiais já publicados - como livros, documentos, publicações em periódicos e artigos científicos - como forma de esclarecer conceitos e ideias ligados à problemática de pesquisa. A leitura das categorias temáticas eleitas dar-se-á por meio dos conceitos-chave da teoria de Giorgio Agamben.

O estudo, inicialmente, explica a concepção de biopoder em Foucault e de exceção para Agamben. Explica-se como se dá a relação das democracias atuais frente à permanência de resquícios totalitários, analisando o conceito clássico de Justiça de Transição.

Em seguida discute-se os conceitos de temporalidade e técnicas de governo. Ainda sobre as peculiaridades do conflito armado e político no direito internacional, bem como quais as propostas apresentadas pelo governo local nas propostas de acordo de paz e suas implicações na legislação colombiana e internacional.

Por fim, foram pensa-se o direito de resistência e suas características no conflito colombiano como forma de problematiza-lo e os aspectos deste estado 
de exceção na concepção de Agamben, para, por fim, lançar algumas notas sobre o cenário justransicional no país.

\section{Agamben e o Direito: do biopoder à exceção}

Antes da criação do Estado Civil o que prevalecia era a lei dos mais fortes. A humanidade vivia, no pensamento de Thomas Hobbes (século XVII) num ambiente de guerra de todos contra todos. Contudo, com a criação do Estado Civil, os indivíduos viram a necessidade de se construir mecanismos capazes de regular a vida em sociedade, visando-se a preservação da vida dos súditos e, sobretudo, a garantia do direito de posse e propriedade.

A criação da norma obedece a regulação da figura do soberano. Para que esta fosse satisfeita, era necessário um indivíduo que decidisse e instituísse as regras para o bom funcionamento da ordem social, dado controle exercido sobre os corpos dos súditos. Todavia, para Schmitt (1996) além das condutas habituais e das normas criadas, existe ainda uma zona cinzenta, onde se encontra imersa a figura do inimigo.

O conceito de zona cinzenta (Agamben, 2010) agrega a ideia do fato que foge à regra, ou seja, que não se adequa as normas criadas, e, portanto, é denominada de exceção. É irracional pensar que o direito estaria apto a identificar o inimigo, ou seja, a situação não prevista na norma, e determinar a situação fática geradora da anormalidade. É necessária uma análise, externa ao fenômeno social, para que então se alcance uma decisão que delimite o inimigo e, assim, garanta as relações políticas.

Este é o papel do soberano, decidir sobre a exceção, bem como criar e garantir a situação como um todo. "Ele detém o monopólio dessa última decisão. É nisso que reside a essência da soberania estatal" (Schmitt, 1996, p. 93). Assim, o soberano é aquele que está no interior e no exterior do ordenamento jurídico, ao mesmo tempo. A importância da decisão soberana está na solução do caos, anormalidade da qual a norma não se aplica pois não a prevê. Saliente-se que além de decidir a exceção, o soberano deve estabelecer quais as condições fáticas normais que devem reinar, para que a norma jurídica possa voltar a ser aplicada.

Surge, então, o estado de exceção, que é essencialmente caracterizado pela suspensão temporária do ordenamento jurídico, por meio de uma decisão soberana. Para Agamben (2010, p. 24), a "[...] norma se aplica à exceção desaplicando-se [...]" e isso significa que a norma possui uma relação com a exceção na forma de sua suspensão. Isto é, o estado de exceção surge como uma situação resultante da suspensão da norma. Agamben assinala que a exceção é uma espécie de exclusão, isto é, uma situação específica que é excluída da norma geral, que não foi prevista. 
As características marcantes do estado de exceção são a sua temporariedade e a sua ausência de localização no ordenamento jurídico. Por sua vez, quando o estado de exceção se confunde com a regra e se torna permanente e localizável, surge o campo, ou seja, um estado de exceção desejado, o espaço absoluto de exceção (Agamben, 2010, p. 26). O campo por sua vez, é a materialização do estado de exceção, que faz com que a situação antes excepcional se transforme em uma situação normal.

Assim, o campo é a criação proposital da situação de exceção, que submete seus habitantes a uma experiência biopolítica absoluta. Ou seja, o campo é também o "[...] mais absoluto espaço biopolítico [...] jamais [...] realizado, no qual o poder não tem diante de si senão a pura vida sem qualquer mediação" (Agamben, 2010, p. 167).

A partir do século XVII o poder soberano decorre da biopolítica, poder que prima pela administração dos corpos e pela gestão da vida (Foucault, 1999; 2005). No século XVIII surge uma série de intervenções e controles reguladores, a que Foucault chama de biopolítica da população. Assim: "As disciplinas do corpo e as regulações da população constituem os dois polos em torno dos quais se desenvolveu a organização do poder sobre a vida" (Foucault, 1999, p. 131).

Diferente do soberano, a biopolítica caracteriza-se não pelo fazer morrer ou deixar viver, mas pelo deixar morrer e fazer viver (Foucault, 1999; 2005). Ela consiste em um ciclo de disciplinas e regulamentações, normalizações, para administrar e gerir a vida orgânica do homem.

Foucault acredita que a biopolítica - o biopoder - é a série de fenômenos, conjunto de mecanismos, através dos quais a espécie humana constitui suas características humanas fundamentais podendo assim entrar numa estratégia política ou estratégia do poder. Em outras palavras é o exercício do poder sobre a vida, é o poder "pacífico" que surge na contramão do poder violento de morte exercido pelo soberano medieval. ${ }^{4}$

Antes de falar em biopoder, Foucault questionava a sua unificação na figura do Estado e do soberano, poder vertical no qual o soberano impunha sua vontade por meio da repressão e da lei. Segundo ele, as relações de poder não se constituem a partir da violência imposta através do direito, mas sim através das disciplinas e de seus efeitos de normalização e moralização. Deve-se, portanto, conjugar "um direito da soberania e uma mecânica da disciplina: é entre esses dois limites, creio eu, que se pratica o exercício do poder, sem, entretanto, que esses limites coincidam entre si" (Foucault, 1999, p. 45).

\footnotetext{
${ }^{4}$ Foucault discutiu o termo biopoder em seus cursos no Collège France, porém, o termo apareceu pela primeira vez em sua obra intitulada “A vontade de saber”, em 1977.
} 
O surgimento da biopolítica, por sua vez, como esclarece Foucault, é:

[...] uma das mais maciças transformações do direito político do século XIX consistiu, não digo exatamente em substituir, mas em completar esse velho direito de soberania - fazer morrer ou deixar viver - com outro direito novo, que não vai apagar o primeiro, mas vai penetrá-lo, perpassá-lo, modifica-lo, e que vai ser um direito, ou melhor, um poder exatamente inverso: poder de "fazer" viver e de "deixar" morrer. O direito de soberania é, portanto, o de fazer morrer ou de deixar viver. $\mathrm{E}$ depois, este novo direito é que se instala: o direito de fazer viver e de deixar morrer" (2000, p. 287).

Aduz a uma nova relação de poder na modernidade, e esse movimento de poder exige uma nova forma de análise, essencialmente diferente em relação às estruturas que governavam na Idade Média.

Diferente de Foucault, Agamben (2010) evidencia que a biopolítica é uma racionalidade de governo já existente nos primórdios da política ocidental. Para ele, não se pode pensar a figura do soberano sem que ela implique a figura correlata do homo sacer, de modo que enquanto houver poder soberano haverá vida nua e exposta ao abandono e à morte. $\mathrm{O}$ homo acer, portanto, é o elemento que efetua a transição do princípio da soberania real do Antigo Regime à moderna soberania do Estado-nação. ${ }^{5}$

A distinção entre soberano e poder, discutida por Foucault, é contestada por Agamben. Para ele, a soberania se preocupou em definir o marco formal filosófico-jurídico que legitima o exercício do poder, enquanto que a biopolítica desenvolveu as técnicas de governo. Contudo, importa destacar que essas técnicas modernas consistem justamente no fato de visarem o governo da vida de uma forma que antes não era possível.

Agamben analisa que o soberano é relevado pela exceção, obtendo o poder para suspender o direito e incluir a vida na exceção. Quando o controle (bio) político da vida humana é sempre o objetivo do estado de exceção, este torna-se uma técnica biopolítica e policial de controlar e governar.

Nesse sentido, o filósofo anuncia que o estado de exceção se apresenta como um "paradigma de governo dominante da política contemporânea". Comumente os Estados tem se utilizado das medidas provisórias e excepcionais como técnicas de governo. Assim, na medida em que os institutos excepcionais se tornam mais habituais, a exceção tende a ser normal, a tornar-se norma.

Agamben (2010) aponta o dispositivo biopolítico da exceção como sendo o principal responsável pela produção da vida nua, ou seja, do homo acer. Ele coloca a vida numa zona de indistinção entre dentro e fora do ordenamento

\footnotetext{
${ }^{5}$ Agamben desenvolve as ideias de homo acer, campo, vida nua e exceção em sua obra conhecida como Homo sacer, a saber, Homo sacer: ilpoteresovrano e lanuda vida, publicado em 1995. Em tal escrito, retoma a herança de Hannah Arendt e Michel Foucault acerca da politização da vida na era moderna e sobre a problemática que Foucault denominou de biopolítica ou biopoder.
} 
jurídico, produzindo uma zona de anomalia na qual a vontade soberana atua sobre a vida dos cidadãos.

Ao analisar o princípio da soberania e a sua ligação com a exceção, o referido filósofo alude que o direito e a política encontram-se numa relação de exclusão - vida natural vs. vida nua - paradigma biopolítico das sociedades contemporâneas.

\section{A perpetuação do Estado de exceção nas democracias atuais: Notas à luz da filosofia de Giorgio Agamben}

Nas democracias ocidentais, século XVIII e XIX, predominava a vontade do soberano, onde este decidia sobre a vida e a morte dos cidadãos, que tinham que se curvar diante da vontade daquele.

Com o decorrer dos anos, por volta dos anos de 1977-1978, a figura do soberano foi perdendo espaço para o biopoder aludido por Foucault. A soberania se baseava no domínio territorial, ao passo que a biopolítica precisa de um Estado populacional, ou seja, se traduz na espera-se da conquista para o crescimento do Estado. Para este, a otimização de suas forças internas serve de referência para o seu autodesenvolvimento. O soberano foi perdendo força sem ser, contudo, extinto.

A política, segundo Agamben, tem triunfado em decorrência do biopoder moderno. Há duas teses principais em seu pensamento. A primeira é de que há um vínculo entre biopolítica e exceção soberana, eventos intimamente relacionados, que se estabelecem com/na política moderna, que revelam que a política atual não conhece outro valor além da vida. A segunda, de que há uma "íntima solidariedade entre democracia e totalitarismo" (Agamben, 2007, p. 12).

As democracias modernas sucederam períodos violadores de direitos. Esses períodos representam para Agamben estados de exceção. Contudo, não se pode dizer que são períodos que violam a lei, vez que, como afirma o filósofo, o estado de exceção apresenta-se como a forma legal daquilo que não pode ter forma legal, se encontra no limite entre a política e o direito, sendo, portanto, o ponto de desequilíbrio entre o direito público e o ato político.

Os estados de exceção instaurados decorreram de manifestações que visavam implementar o absolutismo, onde a vontade de um sobreporia a vontade dos demais. Assim, Agamben define o totalitarismo moderno como sendo "uma guerra civil legal que permite a eliminação física não só dos adversários políticos, mas também de categorias inteiras de cidadãos que, por qualquer razão, pareçam não integráveis ao sistema político" (2004, p. 13). Se trata de uma fusão entre a extensão dos poderes militares e a suspensão de 
normas constitucionais que protegem as liberdades individuais, um patamar de indeterminação entre democracia e absolutismo.

Dentre as características essenciais do estado de exceção está a busca pelo fim da tripartição dos poderes. Esse mecanismo é um resquício dos períodos ditatoriais e abertura legal para instauração de outras ditaduras, afinal, não havendo violação às normas, as violações de direitos ocorridas passam a ocorrer nos termos da lei. Um exemplo claro disso foi a promulgação de um Decreto por Hitler para proteção do povo e do Estado que suspendia os artigos da constituição de Weimar relativos às liberdades individuais.

Para Arendt (1966) os campos de extermínio criados por Hitler representavam o evento totalitário que perfazia a relação entre soberania e exceção. Naquele ambiente, a disposição soberana sobre o corpo dos subjugados redundou em uma fabricação da superfluidade e em uma destruição da natura humana. De acordo com Warat:

Nos regimes totalitários se produz coletivamente uma espécie de 'cegueira histérica'; as pessoas negam-se a ver o horror da realidade a que estão expostas. É uma cegueira que lhes permite aceitar, delirantemente, a ilicitude do regime do terror como legalidade. Terror e lei terminam sendo, histericamente, a mesma coisa (2004, p. 334).

Afinal, a partir dos campos de concentração, o estado de exceção deixa de ser uma situação externa e provisória de perigo e passa a se confundir com a própria norma. Conforme Arendt, o campo é um híbrido de direito e de fato mobilizado pelo argumento de que tudo é possível. A essência do campo é a indistinção entre a norma e a vida nua e a consequente criação de um espaço em que àquela e a norma entram em um limiar de indistinção.

O fato de haver previsão constitucional da possibilidade de instauração do estado de sítio ou de decretos-lei por meio do chefe do executivo federal da margem para uma previsão legal de um possível estado de exceção. Ratifica tal entendimento o acontecido com a Primeira Guerra Mundial, que a princípio se tratava apenas de um decreto que colocava o país em estado de sítio, contudo tal decreto foi transformado em lei e fez com que o estado de exceção de perpetuasse durante cinco anos nos países beligerantes.

Nesse sentido, cumpre destacar as palavras de Rossirer apud Agamben (2004) sobre a transitoriedade das normas que dão vazão a instauração de novos estados limitadores de direitos quando destaca que o caráter temporário de tais normas nem sempre é seguido. A respeito disso, a doutrina ainda diverge quanto ao fato de a permanência da previsão constitucional do estado de exceção da margem para instauração de outras ditaduras, dentre os quais se destaca Schmit (1996), que critica sem restrição a pretensão de se regular por lei o que, por definição, não pode ser normatizado. 
Por outro lado, Julius Harschek criou a teoria objetiva do estado de necessidade 6 , segundo a qual "todo ato realizado em estado de necessidade e fora ou em oposição à lei é contrário ao direito e, enquanto tal, juridicamente passível de acusação" (Agamben, 2004, p. 38-39). Assim, cumpre inicialmente esclarecer o conceito jurídico de necessidade para então se entender a estrutura e o verdadeiro significado do estado de exceção.

A necessidade, por sua vez, pode ser interpretada em dois sentidos opostos, seja pelo fato de não reconhecer nenhuma lei ou por criar sua própria lei, sem ser conduto, fonte desta. Em ambos os casos, "a teoria do estado de exceção se resolve integralmente na do status necessitatis, de modo que o juízo sobre a subsistência deste esgota o problema da legitimidade daquele" (Agamben, 2004, p. 40).

Pode-se dizer então que o estado de exceção, enquanto figura da necessidade, encontra-se como uma medida "ilegal", mas perfeitamente "jurídica e constitucional" caminhando lado a lado da revolução e da instauração de fato de um ordenamento constitucional. Porém, se a revolução é, indiscutivelmente, um estado de fato que "não pode, em seu procedimento, ser regulamentado pelos poderes estatais que tende a subverter e a destruir" é, nesse sentido, e por definição "antijurídico, mesmo quando é justo" (Romano apud Agamben, 2004, p. 45).

Nesse sentido, pode-se destacar que democracia e totalitarismo são coisas distintas. Enquanto no totalitarismo o poder pertence a uma só pessoa, nas democracias modernas o poder é "infigurável" (OST, 2005, p. 13), ou seja, ninguém é capaz de apropriá-lo. Dessa forma, na democracia a esfera do poder, do saber e da lei sofrem constantes questionamentos, diferente do totalitarismo que se constitui da mera aceitação da realidade

Arendt (1966) faz uma reflexão acerca do aniquilamento da legalidade no Estado totalitário e reconhece que tal conduta põe em xeque o positivismo jurídico, pois ele combina decisões com normas que estão no ordenamento. Assim, ciente da existência de normas que podem vim a regular e legitimar a instauração de estados de exceção e objetivando a não repetição de tal período, bem como a reparação pelos danos causados aos civis, decorrentes das violações de direitos humanos, criou-se a justiça de transição.

\footnotetext{
${ }^{6}$ A teoria objetiva fundamenta o estado de exceção no princípio do estado de necessidade. Assim, a existência da necessidade fundamenta a criação das leis ao mesmo tempo em que não reconhece nenhuma lei, pois cria a sua própria lei. O próprio Presidente Getúlio Vargas fundamentava suas decisões na teoria da necessidade, utilizando-se de um axioma de origem latina que dizia: "necessitas legem non habet", ou seja, a necessidade não tem lei. Nesse sentido, Agamben (2004) reconhece as duas teses da necessidade afirmando que a partir delas o Estado está apto a implementar o estado de exceção estando assim justificado em suas ações não as considerando como crime.
} 


\section{O conceito clássico de justiça de transição e aos quadros permanentes de violação de direitos humanos pós-conflito}

Incialmente cumpre destacar que a Justiça de Transição pode ser considerada como aquela que abrange toda a gama de processos e mecanismos associados com as tentativas de uma sociedade para resolver os problemas decorrentes de um passado de abusos em grande escala, para que os autores sejam responsabilizados por suas ações, servindo à justiça e buscando a reconciliação (SGNU, 2004).

Entende-se, então, que os mecanismos da justiça de transição tratam o legado de violações dos direitos humanos e do direito humanitário internacional visando a superação de um regime autoritário. Assim, a justiça de transição atua nas graves violações de direitos humanos e do direito humanitário internacional, buscando a proteção de seus direitos e princípios fundamentais básicos, quais sejam: justiça, verdade e reparação.

Para tanto, faz uso de mecanismos e políticas com objetivos específicos. Dentre estes está o fortalecimento do estado de direito; o avanço dos processos de reconciliação, garantindo os direitos à verdade, a justiça e a reparação integral das vítimas; a eliminação das causas de injustiças sociais de caráter estrutural, que, por sua vez, resultam em garantias à não-repetição de violações, dentre outras (Carvalho, 2016).

Saliente-se que o caminho para se conseguir realizar esses objetivos é por meio da criação de uma situação de diálogo e de abertura democrática que possibilite pensar a reestruturação política e constitucional dos países no período imediato pós-conflito. Contudo, os resultados positivos não podem ser alcançados, a menos que a população confie que a reparação das queixas possa ser obtida por meio de estruturas legítimas para a solução pacífica de disputas e a justa administração de justiça (Van Zyl, 2008).

Ao mesmo tempo, a maior vulnerabilidade de minorias, mulheres, crianças, prisioneiros e detidos, pessoas deslocadas, refugiados e outros, que é evidente em todas as situações de conflito e pós-conflito, traz um elemento de urgência ao imperativo de restauração do Estado de Direito.

A restruturação das democracias requer atenção a inúmeros déficits, entre os quais falta de reformas políticas, de independência institucional da justiça, ausência de capacidade técnica interna, de recursos materiais e financeiros, de confiança pública no governo, de respeito oficial pelos direitos humanos e, em geral, falta de paz e segurança (Patiño, 2010).

O campo justransicional, no decorrer da última década, se ampliou e desenvolveu basicamente por dois motivos, primeiro no que se refere a forma de obrigação legal vinculante, pois, o Direito Internacional evoluiu no decorrer dos útlimos 20 anos ao ponto de atualmente existirem padrões claros relativos às orbigações dos Estados a 
respeito da forma de enfrentar as violações de direitos humanos, tudo isso se deu graças à intervenção do Tribunal Europeu de Direitos Humanos, da Corte Interamericana de Direitos Humanos e o Comitê de Direitos Humanos (Van Zyl, 2008).

O segundo motivo advém do fortalecimento da democracia em muitos lugares do mundo, em especial na América Latina, bem como pelo surgimento de organizações da sociedade civil que contibuíram para inaugurar as instituições e a vontade política necessária para confrontar um legado de violações de direitos humanos e conseguir que as políticas de reparação e não repetição repercutam em ações.

A justiça de transição, em especial, no ordenamento jurídico brasileiro, começou a tomar forma ainda no processo de redemocratização tendo como marco inicial do eixo de reparações, a Lei de Anistia (Lei nº 6.683/1979), vez que previu, para os cidadãos que sofreram sanções políticas a partir de 1964, hipóteses de readmissão em serviço público e de restituição de direitos políticos. Tal eixo de reparações foi ratificado pelo artigo $8^{\circ}$ do Ato das Disposições Constitucionais Transitórias (ADCT) que garantiu medidas de compensação a todos/as os/as atingidos/as por atos de exceção no período de 1946 até 1988, marco jurídico-político da justiça de transição no Brasil (Carvalho, 2016).

Além de tal previsão, a Lei $n^{0}$ 6.683/1979 também previu a concessão de anistia aos agentes que cometeram graves violações de direitos humanos no período ditatorial, tornando-se assim um obstáculo às iniciativas de investigação e de persecução penal dos responsáveis pela prática de crimes de Estado. Destaque-se o texto original da lei que prevê, dentre os anistiados pelas práticas de crime, os militares:

Art. $1^{\circ}$ É concedida anistia a todos quantos, no período compreendido entre 02 de setembro de 1961 e 15 de agosto de 1979, cometeram crimes políticos ou conexo com estes, crimes eleitorais, aos que tiveram seus direitos políticos suspensos e aos servidores da Administração Direta e Indireta, de fundações vinculadas ao poder público, aos Servidores dos Poderes Legislativo e Judiciário, aos Militares e aos dirigentes e representantes sindicais, punidos com fundamento em Atos Institucionais e Complementares (grifos nossos) (BRASIL, 1979, online).

Ademais, importa proferir que tal aplicação não foi prevista pelo artigo $8^{\circ}$ do ADCT, restando claro que a autoanistia, ou seja, a anistia dos agentes do Estado, não foi recepcionada pela Constituição Federal de 1988. Saliente-se, ainda, que Resoluções da Corte Internacional de Direitos Humanos afirmam a incompatibilidade de leis desse instituto com a Convenção Americana de Direitos Humanos:

Art. $8^{\circ}$ É concedida anistia aos que, no período de 18 de setembro de 1946 até a data da promulgação da Constituição, foram atingidos, em decorrência 
de motivação exclusivamente política, por atos de exceção, institucionais ou complementares, aos que foram abrangidos pelo Decreto Legislativo n. ${ }^{\circ} 18$, de 15 de dezembro de 1961, e aos atingidos pelo Decreto-Lei n. ${ }^{\circ} 864$, de 12 de setembro de 1969, asseguradas as promoções, na inatividade, ao cargo, emprego, posto ou graduação a que teriam direito se estivessem em serviço ativo, obedecidos os prazos de permanência em atividade previstos nas leis e regulamentos vigentes, respeitadas as características e peculiaridades das carreiras dos servidores públicos civis e militares e observados os respectivos regimes jurídicos (grifos nossos) (BRASIL, 1988, online).

No decorrer dos anos a política justransicional no Brasil foi ganhando cada vez mais espaço, sendo criada, em 1995, através da Lei n 9.140/1995, a Comissão Especial sobre Mortos e Desaparecidos Políticos (CEMDP), bem como, posteriormente a Comissão de Anistia, no Ministério da justiça, por meio da Lei $\mathrm{n}^{\circ} 10.559 / 2001$.

Nesse sentido, diversas iniciativas, campanhas e ações políticas foram implementadas, motivadas pela Recomendação do Relatório Final da CNV, publicado em 2014, para alterar os nomes de logradouros públicos que homenageavam pessoas ligadas à repressão durante a ditadura. Assim, em atendimento a Recomendação 28 do Relatório, que busca a "Preservação da memória das graves violações de direitos humanos", deve-se adotar medidas visando:

a) cassar as honrarias que tenham sido concedidas a agentes públicos ou particulares associados a esse quadro de graves violações, como ocorreu com muitos dos agraciados com a Medalha do Pacificador; b) promover a alteração da denominação de logradouros, vias de transporte, edifícios e instituições públicas de qualquer natureza, sejam federais, estaduais ou municipais, que se refiram a agentes públicos ou a particulares que notoriamente tenham tido comprometimento com a prática de graves violações (CNV, 2014, p. 974).

Assim, através de seu Relatório, a CNV conseguiu incorporar questões de reforma política à agenda nacional, aumentando as possibilidades de uma exitosa construção da "paz" pós-conflito. Contudo, no que se refere ao eixo judicialização, caminha-se a passos lentos, vez que o Judiciário obsta o andamento das ações penais fundamentando a extinção da punibilidade dos acusados em razão da aplicação da Lei de Anistia. Parte vital da construção da estabilidade pós-conflito é a afirmação de uma força confiável e legítima, e que o fato de não se confrontar os abusos do passado permite aos perpetradores cometer outros crimes.

Por fim, há ainda, no período democrático, a presença de inúmeras instituições que são resquícios da institucionalidade autoritária pós-1964, como é o exemplo as polícias militares e da justiça militar. Contudo, o acesso pleno à 
verdade contribui diretamente para a afirmação de uma memória não obrigada, permitindo que a identidade de um povo seja construída com sua contribuição. Além disso, responsabilizações criminais demonstram que o Estado refuta claramente as práticas autoritárias e ilícitas que outrora chancelara.

É necessário analisar se a justiça de transição também se aplica às democracias que não sofreram violações, mas que estão sofrendo atualmente. Expandir o seu conceito fará com que haja maior recorrência de processos de afirmação dos direitos humanos.

\section{Resultados e discussões}

Os resultados e discussões da pesquisa se dedicam à reflexão do caso colombiano. Assim, a princípio, buscou-se entender os conceitos básicos propostos por Giorgio Agamben em torno da ideia de estado de exceção especialmente no que se refere à temporalidade e as técnicas de governo - para, posteriormente, problematizar os conceitos no caso justransicional colombiano.

Ainda, objetivou-se entender as peculiaridades dos conflitos armados e políticos perante o direito internacional, apresentar aspectos do caso colombiano, bem como o modo pelo qual se deram as propostas de acordo de paz na Colômbia, quais suas implicações na legislação internacional e interna do país.

Por fim, discute-se o uso da força e as noções acerca da distinção entre violência, poder e autoridade, como forma de relacionar o direito de resistência e suas formas de atuação no conflito colombiano, e, partir deste cenário, analisar o conflito entre a noção de estado de exceção e a atuação da justiça transicional colombiana.

\subsection{Técnicas de Governo e Temporalidade, à luz do pensamento de Agamben, frente à existência dos estados de exceção}

O Estado de Exceção, na concepção de Agamben, se fundamenta na existência do estado de necessidade, que se situa no limiar entre o direito e a política, e, por este motivo, não pode ter formulação jurídica pré-definida (Agamben, 2004). Assim, este encontra-se no limite entre a ordem e o direito, vez que surge diante de uma situação excepcional que viola ou ameaça violar a ordem, mas que não está prevista na norma.

No alicerce da exceção, há a vontade soberana, que tem o poder de suspender total ou parcialmente a norma para resolver a situação pelo qual foi invocada. Assim, existem dois critérios essenciais para definir a exceção, quais sejam, a absoluta necessidade de sua instauração e a temporalidade (Agamben, 2004). 
A temporalidade, do latim temporalitas, significa "caráter do que é temporal ou provisório". Esta característica do estado de exceção representa a excepcionalidade da medida, vez que, se tem caráter transitório não deve se conservar no ordenamento jurídico de forma permanente. Tal entendimento decorre do fato de o estado totalitário representar a exceção, onde apenas é invocado em situações extremamente necessárias para fazer cessar o mal ou a ameaça a ordem estatal. E por este motivo, cessado o mal ou ameaça ele deve ser extinto.

A permanência no ordenamento jurídico do estado de exceção faz com que este deixe de ser considerado exceção e passe a se considerar norma, tendo em vista que perdeu sua característica da temporalidade e se tornou permanente, mesmo após a solução do conflito, passando a se assemelhar aos regimes de soberania absoluta (Agamben, 2004).

Nesse sentido, pode-se verificar que o Estado de Exceção é um instituto criado pelo próprio Estado Democrático de Direito, vez que este foi estabelecido a fim de eliminar a arbitrariedade da vontade soberana, sobrepondo a lei de forma isonômica sobre as pessoas. Assim, pode-se constatar que a existência do estado de exceção decorre da pré-existência do estado democrático de direito, vez que sem este, a vontade soberana predomina (Ruiz, 2011).

Os estados democráticos latino-americanos passaram pela etapa de instauração da democracia, e hoje passam pela concretização desta nos ordenamentos jurídicos, vez que ainda há resquícios da atuação da vontade soberana, permanecendo ainda, de forma obscura no Estado, como uma carta na manga para ser utilizada quando necessária (Agamben, 2004).

Sempre que houver ameaça a ordem social por qualquer pessoa ou grupo social, a exceção poderá ser invocada, momento em que o soberano sairá das penumbras do Estado de direito e utilizará sua vontade para suspender total ou parcialmente o direito sobre essas pessoas, através de uma técnica política de governo da vida humana.

Sob esse prisma, o estado de exceção se torna uma técnica biopolítica (Foucault, 2005) e policial (Agamben, 2004) extremamente eficiente para controlar e governar os grupos sociais ditos como perigosos a manutenção da ordem social. Os Estados modernos utilizam a exceção jurídica como uma técnica de governo, se valendo cada vez mais de medidas provisórias e excepcionais. Assim, enquanto essas medidas se tornam habituais, a exceção tende a ser normal e se tornar norma.

Nesse sentido, o estado de exceção se configura como estrutura política fundamental presente em diversas sociedades que se intitulam democráticas, mas que adotam o instituto para os casos de conflitos mais extremos. No centro do poder sempre constará o estado de exceção, por mais invisível que seja a percepção deste, pois este é um espaço vazio, onde uma ação humana, sem 
relação com o direito, se coloca em frente a uma norma sem relação com a vida (Agamben, 2004).

As ditaduras latino-americanas utilizaram o estado de exceção como instrumento jurídico para suspender a ordem, os direitos e garantias constitucionais a fim de defender essa mesma ordem (Ruiz, 2011). Os opositores ao regime eram inscritos na forma da exceção e tinham seus direitos suspensos. Eram usadas formas cada vez mais sofisticadas de excepcionalidade jurídico-política com o intuito de enlaçar a vida humana dos opositores ao regime.

A exceção nos regimes ditatoriais é manifesta ao ponto de se tornar a norma. Todavia, Agamben demonstra que a exceção não se restringe apenas aos regimes ditatoriais, mas ela se perpetua como potência na sombra do Estado de direito e ainda se desenvolve como técnica de governo. Podendo assim, a vontade soberana ser invocada a cada circunstância que se considere necessária para defender a ordem (Ruiz, 2011).

Afirma Agamben (2004, p. 27) que "a declaração de um estado de exceção é progressivamente substituída por uma generalização sem precedentes do paradigma da segurança como técnica normal de governo". Com isso, o filósofo afirma que cada vez mais os Estados se valem de técnicas de governo para justificarem a instauração de estados de exceção.

A existência das favelas do Rio de Janeiro e São Paulo, as contínuas tentativas de criminalizar os movimentos sociais no Brasil, o fato de governar por decretos presidenciais, são atos de exceção vez que o Executivo usurpa a função típica do Legislativo, a existência da FARC por mais de cinquenta anos, entre outros, são exemplos vivos em que a exceção permanece sendo utilizada como técnica de governo de populações perigosas.

"Cada vez que um grupo social representar uma ameaça para a ordem, o Estado de direito invocará a exceção para suspender seus direitos tornando-o vulnerável e como consequência facilmente governável” (Ruiz, 2011, p. 102). A respeito disso Agamben (2004, p. 29) assinala que "uma 'democracia protegida' não é uma democracia”, pois "o paradigma da 'ditadura constitucional' funciona, sobretudo, como uma fase de transição que leva fatalmente à instauração de um regime totalitário".

Resta refletir se diante de tantos casos de instauração de exceções, se estas ainda atendem aos critérios de absoluta necessidade de sua instauração e a temporalidade, e se caso não atendam, se ainda podem ser considerados estados de exceção ou se adquirem um aspecto de normalidade diante da permanência e aceitação social.

O conceito de temporalidade para Agamben (2004) é uma contradição direta para se pensar o estado de exceção colombiano, vez que este perdura por mais de 52 anos, deixando, portanto, de ser um episódio transitório, passando 
assim a incorporar a política do país. Questionamo-nos: a permanência desses estados de exceção é legitimada pela norma?

Acredita-se que a própria norma instaura a exceção como medida de segurança a ordem de maneira controlada, mas, em outros casos, a instauração se dá de maneira incisiva, que toma forma e com o decorrer do tempo se perpetuam e adquirem aspecto legal, vez que não mais se enquadram nos critérios para decretação da exceção, que é o que ocorre no conflito das FARC frente ao estado da Colômbia.

\subsection{Implicações dos conflitos na execução da justiça justransicional colombiana}

A justiça transicional busca acompanhar a transição dos regimes absolutistas para os regimes democráticos, de modo que estes últimos se consolidem para que então a justiça de transição atue reparando as violações de direitos humanos ocorridas naqueles. Objetiva ainda o não retorno do período absolutista, bem como, o exercício da memória para que a sociedade tenha sempre em mente as atrocidades que ocorreram nos períodos ditatoriais, para que estes nunca mais voltem a acontecer.

A partir disso, percebe-se que a justiça de transição nasce após a existência de um conflito. E, por isso, a justiça transicional deve ser entendida como o esforço para construir uma paz sustentável após um período de conflito, seja ele armado ou não, violência em massa ou violação sistemática dos direitos humanos. Afinal: "O objetivo da justiça transicional é o de levar a justiça os causadores das violações, revelar a verdade sobre crimes passados, reparar às vítimas, reformar as instituições abusivas e promover a reconciliação" (Van Zyl, 2008, p. 23).

A respeito do conflito, o Comitê Internacional da Cruz Vermelha (CICV) publicou um artigo de opinião em março de 2008, explicando como se definem os conflitos armados no Direito Internacional Humanitário (DIH). Este último é o ramo do direito internacional que governa os conflitos armados, e para isso estabelece duas categorias de conflitos, os conflitos armados internacionais e os conflitos armados não internacionais (CICV, 2008).

Quanto aos primeiros, estes irão existir sempre que "um ou mais Estados recorrem à força armada contra outro Estado, sem importar a intensidade do confronto" (CICV, 2008). É o que preceitua o artigo $2^{\circ}$ comum às Convenções de Genebra de 1949 quando prevê que a Convenção "se aplicará em caso de guerra declarada ou de qualquer outro conflito armado que surja entre duas ou várias das Altas Partes Contratantes, mesmo que o estado de guerra não seja reconhecido por uma delas". O artigo se refere aos conflitos armados internacionais, e reconhece que o conflito será definido como armado ainda que um dos Estados envolvidos não concordem. 
Cumpre destacar os conflitos armados não internacionais, definidos no artigo $3^{\circ}$ como sendo o conflito de caráter internacional que surge no território de uma das Altas Partes Contratantes. Assim, enquadram-se nesse conceito os conflitos armados que tenham envolvimento das forças armadas governamentais e de um ou mais grupos armados não governamentais, ou apenas entre estes grupos (CIVC, 2008).

Para se distinguir os conflitos armados das formas menos graves de violência, como tensões e distúrbios internos, tumultos ou atos de banditismo, dois critérios são utilizados, quais sejam, a intensidade e a organização dos sujeitos do conflito. É necessário que as hostilidades atinjam um nível mínimo de intensidade, como ocorre, por exemplo, quando o governo é obrigado a empregar força militar contra os insurgentes, ao invés de apenas as forças policiais.

Quanto aos sujeitos do conflito, é necessário que os grupos não governamentais envolvidos no conflito sejam considerados "partes do conflito", ou seja, que possuam forças armadas organizadas, que estejam sob uma estrutura de comando e que tenham capacidade de manter operações militares (CICV, 2008).

Ainda, o Tribunal Penal Internacional para ex-Iugoslávia, por meio da decisão sobre o movimento de defesa para apelo interlocutório sobre jurisdição, definiu que o conflito armado não internacional existirá "sempre que haja [...] violência armada prolongada entre autoridades governamentais e grupos armados organizados, ou entre tais grupos dentro de um Estado" (1995, parágrafo 70).

Nesse sentido, cumpre destacar o caso colombiano das Forças Armadas Revolucionárias da Colômbia (FARC). Essa organização tinha como discurso ideológico a implantação, mediante táticas de guerrilha, do socialismo na Colômbia, promovendo a distribuição igualitária de renda, a reforma agrária, o fim de governos corruptos e das relações políticas e econômicas com os Estados Unidos, entre outros aspectos sociais.

A população colombiana via esta organização como uma alternativa para reparar as desigualdades sociais do país. Em 1980, a exploração do narcotráfico e a violência se intensificaram, o que fez com que o grupo perdesse o foco de sua atuação, e passasse a ser considerado como organização terrorista pelos governos da Colômbia, Estados Unidos, Canadá e União Europeia. Discordaram dessa nomenclatura os governos do Equador, Bolívia, Brasil, Argentina, Chile, Cuba e Venezuela, tendo estes dois últimos intitulado as FARC como "insurgentes" (CNMH, 2013).

Destaque-se que as FARC, independente da nomenclatura dada pelos Estados, nos termos do Comitê Internacional da Cruz Vermelha se caracteriza como um conflito armado não internacional (CICV, 2008), vez que, há a 
presença prolongada por mais de 50 anos do conflito armado entre um grupo armado organizado e o governo, no Estado da Colômbia.

Quanto aos critérios para se caracterizar o conflito armado não internacional, tem-se a intensidade do conflito existente entre as FARC e o governo colombiano, diante das eminentes violações de direitos humanos decorrentes deste quadro. Bem como a estrutura de comando pela qual as FARC se organiza, tendo divisões entre o secretariado, bloco, frente, coluna, companhia, guerrilha e pelotão (CNMH, 2013).

Assim, há anos, as tentativas de Acordos de paz têm visado acabar com este conflito interno que causou sequelas na população colombiana pela violência estatal e civil, sequestro e morte de milhares de pessoa e reforço do tráfico de drogas (CNMH, 2013). A última tentativa de acordo de paz que foi referendada possuía quatro pontos principais, quais sejam: o cessar-fogo (e das hostilidades) bilateral e definitivamente; o desarmamento das FARC; as garantias de segurança e luta contra organizações criminosas responsáveis por homicídios e massacres ou que ameaçam defensores dos direitos humanos e movimentos sociais e políticos; e o Combate a condutas criminais que ameacem a construção da paz.

Contudo, após o referendo, com $50,2 \%$ dos votos válidos, a população colombiana optou pela não ratificação do Acordo, vez que, dentre os pontos mais controvertidos, estava a transformação das FARC em um partido político com cinco cadeiras no Senado e cinco na Câmara nas duas legislaturas seguintes. Bem como, a concessão de anistia aos culpados de crimes de guerra ou contra a humanidade, tanto das FARC como das forças do Estado.

A população rejeitou o espaço político que as FARC teriam sem, contudo, serem questionadas as ações estatais. Um relatório de 2013 do Centro Nacional de Memória Histórica (CNMH) cita que os anos de conflito armado entre as FARC e o governo colombiano resultaram em 220.000 mortos; 25.000 desaparecidos; 30.000 sequestrados e 5,7 milhões de deslocados (Caro Peralta, 2013).

Assim, se o Acordo tivesse sido firmado, ganharia importância tanto no âmbito internacional como internamente na Colômbia. No âmbito internacional, os documentos pactuados ganhariam forma de "acordo especial" perante o Direito Internacional Humanitário, sendo submetido à apreciação do Secretário-Geral da Organização das Nações Unidas (ONU). Bem como, o Acordo seria atrelado à Resolução 2261 do Conselho de Segurança, visando que a paz atingida gerasse um documento oficial aos olhos da ONU (RADAR GSMU, 2016).

No âmbito interno, o Acordo ganharia status de Lei Constitucional, inserido por meio de Emenda à Constituição, sob a ótica de "acordo especial". Esta estratégia foi pensada para assegurar que o conteúdo do Acordo fosse 
cumprido e devidamente integrado ao ordenamento jurídico colombiano, para que não se tornasse vulnerável às oscilações políticas e sociais. Sendo assim, a repercussão da ratificação do Acordo pela população ganharia proporções muito maiores que apenas a extinção do movimento revolucionário, interferiria nos ordenamentos jurídicos colombiano e internacional (RADAR GSMU, 2016).

\subsection{O caso justransicional colombiano à luz das contribuições do pensamento de Giorgio Agamben}

A história da humanidade é composta por eventos únicos que constituem rupturas e ressurgimentos em meio as continuidades. Historicamente sistemas econômicos, as filosofias políticas e o ordenamento jurídico se desdobram e servem ao sistema bélico. Arendt (2004), cita alguns filósofos, dentre estes, Max Weber - que afirma que "o Estado é o domínio de homens sobre homens com base nos meios de violência legítima, isto é, supostamente legítima" (2004, p. 23).

Assim, Arendt acredita que poder é diferente de força, que é diferente de violência, que, por sua vez, é diferente de autoridade. Para a filósofa, estes são fenômenos distintos e diversos entre si. Poder, força, autoridade e violência nada mais são do que palavras que indicam os meios pelos quais o homem governa o homem. Assim, o poder é a habilidade humana de agir em comum acordo sem fazer uso da força, ou seja, o poder emana do povo, e é este grupo que o detém. Enquanto o grupo estiver unido, há poder, se o grupo desaparecer, desaparece também "o seu poder" (Arendt, 2004, p. 24).

A força é algo proveniente da natureza, representando assim a energia liberada através de movimentos diversos. A autoridade nada mais é do que a obediência inquestionável que não faz uso da violência, tendo em vista que onde houver violência não há autoridade. Nesse sentido, a autoridade depende da existência de respeito, seja pela pessoa ou pelo cargo (Arendt, 2004).

Por último, a violência, surge, na maioria das vezes, como último instrumento para conservar a estrutura do poder. Assim, pode ser considerada como um instrumento individual, um meio de impor à vontade, que normalmente não é duradouro e não cria nada em definitivo. Apesar de surgir para manutenção do poder, não se confunde com este, vez que o poder é a essência de todo o governo, já a violência é por natureza um instrumento, a qual depende da justificação e da orientação para o fim que almeja (Arendt, 2004).

Através da reflexão desses instrumentos é possível perceber que nenhum governo pode existir baseado apenas na violência. O poder é a essência do governo, e as condições básicas para um poder legítimo, para Arendt (2004), é de ser íntegro, consentido pelo apoio popular e fundado na livre troca de 
opiniões entre iguais. A violência e o poder articulam-se num jogo político, onde o mais puro totalitarismo necessita de apoio, assim como as revoluções, mesmo que consensuais, não se isentam da violência.

A esse respeito, cumpre destacar o mecanismo do direito de resistência que decorre da relação de poder que existe entre o indivíduo e o Estado. Este último quanto a sua atuação na sociedade no exercício de sua autoridade soberana, o primeiro, quanto ao dever de obediência. Ressalte-se que este dever se limita às ordens estatais justas. Assim, resta o questionamento: se ainda que as normas não sejam justas, o indivíduo será obrigado a obedecê-las?

É nesse contexto que desponta o direito de resistência. Direito afirmado de diferentes formas ao longo da história, desenvolvido a partir do século XVII, que qualquer pessoa tem de resistir ou insurgir contra qualquer fator que ameace sua sobrevivência ou que represente uma violência a valores éticos ou morais humanistas, de forma pacífica e não violenta, através de atos e questionamentos de pontos específicos do governo.

Assim, a desobediência civil é algo resguardado pela norma, contudo, tem que ser pacífica e sem violência, visando demonstrar a insatisfação popular com o regime, e por esse motivo, a utilização de armas no embate descaracteriza o direito de resistência, pois este dentro dos marcos constitucionais, estabelece os limites da ação política, que deve estar em conformidade com os princípios democráticos.

A desobediência civil ${ }^{7}$, no que concerne ao direito de resistência, é um mecanismo indireto de participação da sociedade, embasado por ideais de liberdade e racionalidade, que representa uma manifestação legalmente aceita contra o próprio regime imposto por um governo. Assim, é uma forma de pressão legítima, de protesto, de rebeldia contra as leis, atos ou decisões que ponham em risco os direitos civis, políticos ou sociais do indivíduo.

Contudo, a legitimidade da desobediência civil encontra-se prevista ainda em outros ordenamentos constitucionais como no caso da Alemanha. A esse respeito Agamben (2004, p. 24) traz a ideia de que "é impossível regular juridicamente alguma coisa que, por sua natureza, escapa à esfera do direito positivo".

O filósofo compara a legalização da desobediência civil com a legalização do estado de exceção, seja em lei específica ou na Constituição. Agamben afirma que

[...] se a resistência se tornasse um direito ou terminantemente um dever (cujo não cumprimento pudesse ser punido), não só a constituição acabaria pode se

\footnotetext{
${ }^{7}$ Sob a ótica constitucional brasileira, pode-se afirmar que o direito a desobediência civil encontra respaldo no artigo $5^{\circ}$, XXXIV, da Constituição Federal de 1988 quando prevê o direito de petição aos poderes públicos, que se destina a defesa de direitos ou contra a ilegalidade ou abuso de poder. Portanto, podemos dizer que se trata de direito fundamental
} 
colocar como um valor absolutamente intangível e totalizante, mas também as escolhas políticas dos cidadãos acabariam sendo juridicamente normalizadas (2004, p.24).

Com isso, o autor quer dizer que em ambos os casos, de legalização do estado de exceção e da desobediência legal, o que se questiona é a validade jurídica das medidas que, em regra, são extrajurídicas e excepcionais.

Nesse contexto cumpre destacar o conflito colombiano - FARC e o Estado - existente há décadas. Desde a independência colombiana, em 1819, o país possui um histórico de instabilidades políticas e conflitos sociais, o que desencadeou o surgimento das FARC, um movimento que se iniciou no meio rural, a fim de buscar a melhor distribuição de renda, a reforma agrária e o fim da corrupção e das relações com os Estados Unidos.

A resistência é intimamente ligada com a discordância com o poder ou com a política capitalista macro do país que impulsiona esses movimentos. A resistência bélica, por sua vez, é uma forma de como o capitalismo - e o Estado - conduz a situação dos grupos de resistência, estando, no caso em análise, extremamente ligada a influência dos Estados Unidos na Colômbia, sendo este, inclusive, um dos principais motivos da revolução.

$\mathrm{O}$ uso da violência por parte do Estado representa a impossibilidade de diálogo entre o soberano e seus súditos. Afora isto, resta observar, se o caso colombiano pode ser considerado como um estado de exceção aos olhos de Agamben. Sabe-se que no conceito deste filósofo, para se caracterizar o estado de exceção, deve-se preencher alguns requisitos, quais sejam, temporalidade e necessidade da medida.

É evidente que o conflito não se enquadra nem em uma característica nem na outra, vez que perdura por mais de 50 anos, não podendo mais ser considerado temporário, bem como, não é necessário, tendo em vista que a exceção é instaurada quando alguma situação excepcional a regra surge. No caso em comento a excepcionalidade não mais existe, tendo em vista que as violações por parte do Estado são recorrentes, e a exceção se tornou regra.

A esse respeito, resta o questionamento: onde está o limite do soberano? Em outras palavras, qual é o limite da atuação do Estado de acordo com a norma? A exceção, por si só, rompe com um ideal constitucional instaurado, contudo, temporariamente. Na Colômbia este rompimento tem se perpetuado fazendo com que o soberano, na concepção de Agamben, tome força e passe a governar livremente, o que descaracteriza a democracia.

Para Agamben (2004) o limite do poder do soberano é a norma, que regula as situações sociais habituais. Contudo, Schmitt (2003) discorda de tal pensamento quando traz a Teoria constitucional em seu aspecto político, onde vem dizer que a Constituição é uma decisão política fundamental, ou seja, serve 
apenas para estruturar o estado e assegurar direitos fundamentais, não estando relacionada aos anseios sociais ou a limitação do poder.

Nesse sentido, cumpre destacar que o processo de afirmação constitucional na Colômbia se deu através do rompimento de um ideal de colonização, e que este repercute ainda nas normas do país. Assim, o fato de haver normas de viabilizem o uso livre da vontade do soberano, causa um cenário de instabilidades e controvérsias entre o povo e o Estado, tendo como consequência a falta de apoio popular e a instauração de grupos revolucionários.

Sob esse prisma, verifica-se que as características do conflito colombiano fogem à normalidade dos casos de exceção, criando assim uma nova faceta do estado de exceção, a partir da concepção clássica proposta por Agamben, vez que ainda existem diversas violações de direitos humanos no país, que decorrem tanto da própria ação do Estado no combate as revoluções, quanto da ausência deste em atuar de forma incisiva na sociedade de forma a contribuir com um cenário de estabilidade social. Contudo, esta contribuição não significa ser violenta, pois, a violência é uma forma abusiva e violadora de se conseguir legitimar a norma e a soberania do governante, sendo, na verdade, um instrumento de dominação e imposição e não de conquistas de direitos ou de paz social.

A utilização de armas pelos grupos insurgentes e pelo Estado caracteriza o conflito armado não internacional, vez que residem apenas em âmbito interno. Contudo, tal característica possui implicações da justiça transicional da Colômbia. Em sua origem a justiça de transição é um mecanismo que "[...] é composto de julgamentos, purgas e reparações que ocorrem dentro de uma transição de um regime político para outro “ (Elster, 2006. p. 15).

Contudo, atualmente, pode-se considerar a justiça de transição como sendo a justiça responsável por regular a mudança de um regime político para outro, porque a Justiça transitória "esteve presente sempre que uma sociedade passou por um conflito, do autoritarismo ou guerra para os caminhos da paz e democracia” (Fernández Carrasquilla, 2014, p. 170).

A exitência dessas controvérsias interfere diretamente no modo como o Estado se relaciona com os sujeitos no quadro justransicional. Os mecanismos da anistia e do indulto presentes nas propostas de acordo de paz, assim como na justiça de transição, são mecanismos tidos como adequados para facilitar a trasição de um conflito para a "paz". Em âmbito internacional se discute a matéria de proteção os direitos das vítimas, de forma que, quando se colocar fim ao período de confronto, também se garantissem os direitos daqueles que se viram obrigados a suportar as consequências desse conflito, e não apenas aqueles que violaram os direitos humanos.

A aplicação de normas justransicionais na Colômbia foge da normalidade pelo fato de o conflito ainda estar latente no país. Por esse motivo, o sistema 
jurídico colombiano enfrenta tensões, no sentido de que ao mesmo tempo que tem que garantir o direito das vítimas, busca alcançar a paz, que teoricamente é alcançada quando se concede o perdão e o esquecimento para os perpetradores, tanto por parte do Estado quanto por parte dos revolucionários.

Assim, no que se refere ao caso colombiano, tem que se levar em contasua transição histórica. A Colômbia passou por um processo de colonização fortíssimo que não se esvaiu, tendo em vista que ainda há uma manutenção da colonização no processo de formação constitucional colombiano, e esse fator é determinante no modo como o Estado vai fazer a transição para o regime democrático. Pois, há um contexto de pensamentos extremistas, sejam estes de esquerda ou de direita, que dificultam este processo,

Ante o exposto, verificou-se que o conflito colombiano é ímpar, não se enquadrando nos conceitos clássicos. Este fato, contudo, não interfe a aplicação da justiça transicional na Colômbia. A análise dos regulamentos colombianos nesta matéria, deve inevitavelmente ser feita à luz de uma particularidade dadinâmica do conflito no país para que não hajam equívocos em sua aplicação. Com isso almeja-se o cessar das constantes violações e a reparação aos que, durante todo esse tempo, sofreram com a existência desse conflito com o Estado que trouxe mais maleficios que benefícíos aos cidadãos colombianos.

\section{Considerações finais}

O Estado de Exceção para Agamben encontra-se numa zona de indistinção chamada de zona cinzenta, vez que permeia uma situação que foge à regra. Da necessidade de se entender e regular o desconhecido surge o soberano, que é aquele capaz de suspender a norma, total ou parcialmente, para julgar a excepcionalidade nos termos da norma que entender aplicável, vez que aquela não tem forma legal pré-definida.

Fundamentada no estado de necessidade, a exceção possui como características marcantes, a absoluta necessidade de sua instauração e a temporalidade. Por representar aquilo que não deve ser normatizado, o estado de exceção deve ser temporário, de forma que sua permanência no ordenamento jurídico o descaracteriza, passando a se considerar norma. No mesmo sentido, a sua instauração fundamenta-se na extrema necessidade, vez que nos estados totalitários, por exemplo, não há necessidade de sua instauração pois nestes a exceção é regra, não havendo extrema necessidade de criar a figura do soberano.

Nesse ínterim, cumpre destacar que a exceção nasce junto com os regimes democráticos de direito, atuando nestes ainda de forma disfarçada através das técnicas de governo, onde os governos se valem cada vez mais do uso de medidas teoricamente provisórias e excepcionais, fundamentadas na defesa da 
ordem. Diante disso, é perceptível que nesses aspectos o estado de exceção perde suas características e deixa de ser um de ser um episódio transitório e passa a incorporar a política do país, como ocorre por exemplo com o conflito na Colômbia.

A invocação do soberano pressupõe uma previsão legislativa, ou seja, que haja algum resquício de totalitarismo ou colonialismo nas normas internas do país, como ocorre no Brasil e na Colômbia, quando permitem que o soberano atue, no que se refere a este último, por anos de forma ilimitada, pois a norma que o legitima é incapaz de limita-lo, nos termos da teoria constitucional de Schmitt.

O conflito colombiano, foi instaurado em razão da política do país não atender as expectativas dos seus povos. Passou-se a se distinguir das formas menos gravosas de violência, como as tensões e distúrbios internos quando recebeu dos Estados Unidos da América um incentivo bélico ao conflito. Assim, começou a ser reconhecido como um conflito armado não internacional por ter o envolvimento de forças armadas governamentais e de um ou mais grupos armados não governamentais.

A violência que ocorre na Colômbia, tomou proporções maiores e propósitos diferentes do estimado. Após o fim do conflito, habitualmente, temse a instauração de um novo regime, e é nesse momento que surge a justiça de transição, para acompanhar a passagem dos períodos totalitários para os regimes democráticos, objetivando a reparação as violações de direitos humanos ocorridas. Todavia, este é o conceito clássico de justiça de transição, que se aplica a regimes violadores de direitos humanos passados, então, o que fazer com exceções atuais?

Essa é a grande polêmica de quando se fala em justiça de transição na Colômbia, pois, como supramencionado, o conflito existente instaurado a mais de 50 anos ainda perdura, dificultando a atuação da justiça de transição pois foge ao comum, vez que, cria uma nova concepção de estado de exceção e de justiça de transição, que diferem dos conceitos clássicos.

Nesse sentido, é necessário analisar em quais proporções se dá as marcas da colonização no processo de formação constitucional do país, pois isto, influenciara diretamente no modo como o Estado irá realizar a transição.

Os acordos de paz que vem tentando ser firmados acerca da guerrilha colombiana afetam não apenas a própria Colômbia, mas também o cenário internacional e países que detém relações diplomáticas com o país. Dessa forma, ocorrendo a pacificação do conflito armado colombiano abrir-se-á um espaço importante no cenário, político e econômico para cooperação entre os nações afins. 


\section{Referências}

Agamben, G. (2004). Estado de exceção. Sao Paulo: Boitempo, 2004.

Agamben, G. (2010). Homo sacer: o poder soberano e a vida nua I. 2. Belo Horizonte: UFMG.

Arendt, H. (1966). The origins of totalitarianism. Cleveland: Meridian.

Arendt, H. (2004). Da violência. Brasília: Editora Universidade de Brasília.

BRASIL. Relatório - Comissão Nacional da Verdade. Brasília: CNV, 2014, 976, (Relatório da Comissão Nacional da Verdade; v. 1).

. Constituição (1988). Constituição da República Federativa do Brasil. Brasília, DF: Senado Federal: Centro Gráfico, 1988.

. Emenda Constitucional $\mathrm{n}^{\circ} 26$, de 27 de novembro de 1985. Altera a redação do art. $6^{\circ}$ da Constituição Federal.In: Constituição da República Federativa do Brasil. Brasília, DF: Senado Federal: Centro Gráfico, 1988. . Lei $\mathrm{n}^{\circ}$ 9.140, de 04 de dezembro de 1995. Reconhece como mortas pessoas desaparecidas em razão de participação, ou acusação de participação, em atividades políticas, no período de 2 de setembro de 1961 a 15 de agosto de 1979, e dá outras providências. Diário Oficial da república Federativa do Brasil. Brasília, DF, 05 dez. 1995. Disponível em: $<$ http://www.planalto.gov.br/ccivil_03/leis/L9140.htm>. Acesso em: 17 set. 2017.

. Lei n ${ }^{\circ} 12.528$, de 18 de novembro de 2011. Cria a Comissão Nacional da Verdade no âmbito da Casa Civil da Presidência da República. Diário Oficial da República Federativa do Brasil. Brasília, DF, 18 nov. 2011. Disponível em: <http://www.planalto.gov.br/ccivil_03/_ato20112014/2011/lei/112528.htm> Acesso em: 17 set. 2017.

Carvalho, C., Guimaraes, J. O. e Guerra, M. (2016). Justicia de transiciónen América Latina: panorama 2015. Brasília: Ministério da Justiça, Comissão de Anistia, Rede Latino-Americana de Justiça de Transição (RLAJT).

Centro Nacional de Memoria Histórica (2013). ¡Basta ya! Colombia: Memorias de guerra y dignidad. Bogotá: CNMH..

Collazos, A. e Valdivieso, M. (2012). "La justiça transicional em Colombia. Los estândaresinternacionales de derechos humanos y derecho internacional humanitário em la política de Santos". Papel Político, vol. 17, nº 2, p. 621-653.

Duarte, F. C. e Fonseca, F. (2014). "Fenomenologia hermenêutica: o direito na visada de ser e tempo de Heidegger". Revista Novos Estudos Jurídicos Eletrônica, vol. 19, n. 2, p. 469-496.

Elster, J. (2006). Rendición de cuentas. La justicia transicional en perspectiva histórica. Buenos Aires: Katz Editores. 
Fernández Carrasquilla, J. (2014). Concepto y limites del derecho penal actualy nociones de justicia transicional, perdón y reconciliación. Bogotá: Temis. Foucault, M. (2005). Em defesa da sociedade: curso no Collège de France (1975-1976). São Paulo: Martins Fontes, 2005.

Foucault, M. (1999). A verdade e as formas jurídicas. Rio de Janeiro: Editora Nau.

Foucault, M. (1999). Em defesa da sociedade: curso no Collège de France. São Paulo: Martins Fon-tes.

Foucault, M. (1984). Vigiar e Punir. Rio de Janeiro: Vozes.

Gil, A. (2008). Método e técnicas de pesquisa social. São Paulo: Atlas.

Lakatos, E. e Marconi, M. (2003). Fundamentos de metodologia científica. São Paulo: Atlas, 2003.

Ost, François (2005). O tempo do direito. São Paulo: EDUSC.

Patiño, M. C. (2017). Las víctimas y la justicia transicional: ¿Están cumpliendo los Estados latino-americanos com los estándares internacionales? Informe comparativo. Disponível em: <http://www.dplf.org/sites/default/ files/1285258696.pdf $>$. Acessado em: 12 de junho de 2017.

Radar Global South Unit for Mediation (GSUM) $n^{0} 12$. Centro de Estudo e Pesquisas - BRICS Policy Center. De 05 a 18 de maio de 2016.

Ruiz, C. (2011). "O estado de exceção como paradigma de governo". Revista do Instituto Humanitas Unisinos, ed. 373, s.p.

Schmitt, C. (1996). The concept of the political. Chicago: University of Chicago.

Schmitt, C. (2003). Teoría de la Constitución. Madrid: Alianza.

Secretario General de Naciones Unidas (SGNU) (2004). El Estado de derecho y la justicia de transición em las sociedades que sufren o han sufrido conflictos. Informe del Secretario General al Consejo de Seguridad de Naciones Unidas. 3 de agosto de 2004.

TPI para Ex-Iugoslávia, The Prosecutor v. DuskoTadic, Decisão sobre a Moção de Defesa ao Recurso Interlocutório sobre Jurisdição. 2 de outubro de 1995, par.70. Disponível em <http://www.icty.org/x/cases/tadic/acdec/ en/51002.htm $>$ Acesso em: 28/10/2017.

Van Zyl, P. (2008). "Promoviendo la justicia transicional en sociedades postconflicto, verdad memoria y reconstrucción”. En M. Romero (ed.). Verdad, memoria y reconstrucción. Serie de justicia transicional. Nueva York: Centro Internacional para la Justicia Transicional.

Warat, L. A. (2004). "A fantasia jurídica da igualdade. Democracia e direitos humanos numa pragmática de singularidade”. En: Mezzaroba, O., Rover, A. e Monteiro, C. (Eds.). Epistemologia e ensino do direito: o sonho acabou. Florianópolis: Fundação Boiteux. 
